\title{
Effect of Temperature Semi-solid Casting Process on AZ91D Magnesium Alloys to Hardness and Microstructures
}

\author{
Kusharjanto $^{1 *}$, Sutarno $^{2}$, R. Henny Mulyani ${ }^{3}$ \\ ${ }^{1,2,3}$ Department of Metallurgical Engineering, University of Jenderal Achmad Yani, \\ Jl. Gatot Subroto, PO Box 807 (PINDAD), Bandung, 40285, West Java, Indonesia
}

( Received: November 18, 2016, Revised: February 10, 2017, Accepted: January 14, 2019 )

\begin{abstract}
This study investigates the effect of temperature semi-solid casting process for magnesium alloys AZ91D in an effort to increase the mechanical properties for the application of lightweight structures. In this experiments, semi-solid casting process is varied temperatures ranging from 500, 510, 520, 530 and $540^{\circ} \mathrm{C}$. Results of hardness testing obtained the highest average is $64.4 \mathrm{BHN}$ at a temperature of $500^{\circ} \mathrm{C}$, which higher than the as-cast $42.56 \mathrm{BHN}$ (an increase of $33.91 \%$ ). The increasing of hardness occur because of changes in the microstructure of dendrite structures into globular grains, which have $\alpha-\mathrm{Mg}$ phase and $\beta-\mathrm{Mg}_{17} \mathrm{Al}_{12}$. Small spherical grain shape and spread evenly with a size of $40.08 \mu \mathrm{m}$ obtained at temperatures of $500^{\circ} \mathrm{C}$ and size $77.2 \mu \mathrm{m}$ at temperatures $540^{\circ} \mathrm{C}$.
\end{abstract}

Keywords: magnesium alloys, semi-solid casting, hardness, microstructure

\section{INTRODUCTION}

The need for light vehicles is now a choice of customer. Mild nature will have an impact on the increase in speed. In addition, the transport sector uses $60 \%$ of energy consumption so we need a vehicle that can save energy and lower environmental pollution [1]. So the development of lighter material substitutes are needed to increase the speed of the vehicle, helping time efficiency, reduce fuel consumption and minimize pollution.

The use of substitute materials for vehicle components developed to improve the properties of the material so obtained better results than the previous good properties of mechanical properties, physical properties, chemical and technological properties.

One development of the use of the material used is magnesium which has a low density, corrosion resistant and have good ductility. However, magnesium deficiency is to have strength and low hardness. The addition of other elements and the selection can improve its manufacturing processes, mechanical properties, physical properties, chemical and technological properties [2].
Applications magnesium alloy material is generally used in the frame and body of the vehicle because the vehicle weight is generally influenced by the engine (28\%), weight $(28 \%)$ and the vehicle frame (27\%) [3]. Automotive components have relatively complex shapes or complex, so that the process of casting choice. In the casting process itself, there are various types of processes that can be used to produce the components. Criteria and function of components is an important concern in choosing a component of the manufacturing process. One of the casting process for the manufacture of the components used are semi-solid casting.

Semi-solid casting process is used as a kind of new metal forming method because the results are better than other casting process. Semi-solid casting has many advantages, namely a higher viscosity than the liquid metal, shrinkage when freezing is low, the product dimension precision, producing latent heat low so that no thermal shock to the mold and the material can fill the mold cavity elaborately shaped and thin [4].

Operating temperature semi-solid casting will determine the final microstructure of magnesium

\footnotetext{
* Corresponding author

E-mail address: kusharjanto@lecture.unjani.ac.id
} 
alloys. In the diagram $\mathrm{Mg}-\mathrm{Al}$ [5], the temperature of the semi-solid casting process is in the range 500$600^{\circ} \mathrm{C}$ (solid-liquid region). The amount of solidliquid temperature range, it is important to know the temperature of the semi-solid casting which will affect the changes in the microstructure and mechanical properties of magnesium alloys.

\section{THEORY}

\section{Semi-solid casting}

Semi-solid casting process using a temperature range in an area that has two solid phase-liquid (mushy zone) is an important parameter which is defined as operating temperature. Operating temperature range can be determined by reference to binary phase diagram $\mathrm{Mg}-\mathrm{Al}$ as shown in Fig. 1 .

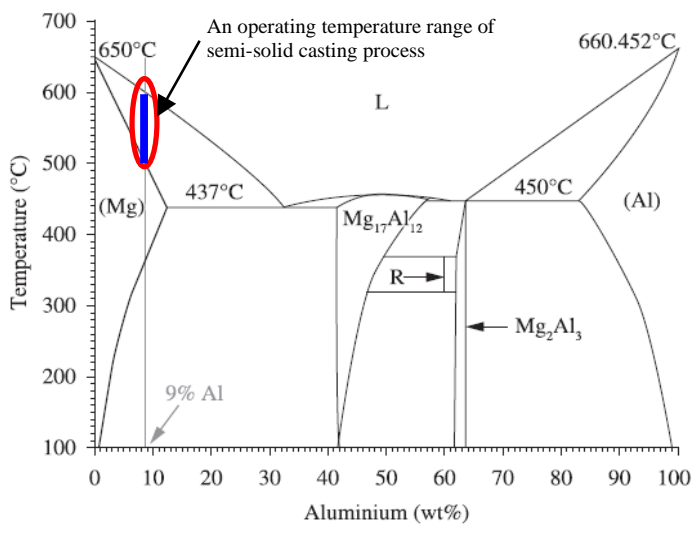

Figure 1. A phase diagram of $\mathrm{Mg}-\mathrm{Al}$ [5].

Semi-solid casting process as a kind of new metal forming method, has attracted worldwide attention since it was first conceived by David Spencer in the 1970s and M.C. Fleming in 1991. Compared with conventional casting, semi-solid casting has many advantages, namely a higher viscosity than the molten metal, the metal laminar flow leading to the mold cavity, freezing low shrinkage, dimensional precision products. Compared with conventional forming processes are carried out in a state of solid, semi-solid casting requires style formation is lower, can fill the mold cavity elaborately shaped and thin. In connection with the mechanical properties of the resulting semisolid casting process of approaching the process of forging products.

Semi-solid casting process has been a technological breakthrough in the manufacture of components that require high precision (net-shape product) and have high mechanical properties. It can be said semi-solid casting is a combination of two processes, namely the casting and forming. Schematically semi-solid casting process can be seen in Fig. 2.

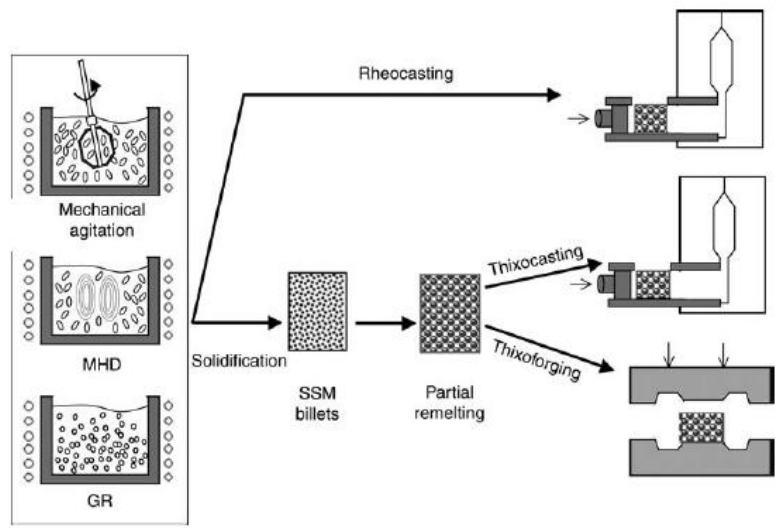

Figure 2. The type of semi-solid casting [6].

\section{EXPERIMENTAL METHOD Experiment}

The experiments were performed using pure magnesium, pure aluminum and pure zinc. Making the alloy $\mathrm{Mg}-\mathrm{Al}-\mathrm{Zn}$ performed in electric resistance furnace as much as $2 \mathrm{~kg}$ with a composition of $90 \%$ $\mathrm{Mg}, 9 \% \mathrm{Al}$ and $1 \% \mathrm{Zn}$. Defined melting temperature $750^{\circ} \mathrm{C}$. During the thawing process flowing argon gas to prevent oxidation. Stirring for 30 seconds to homogenize the magnesium alloy. After it was poured into metal molds dimension $\varnothing 20 \times 200 \mathrm{~mm}$ (ascast) be going to a semi-solid casting process (Fig. 3). Sample results of the casting and then cut to size $\varnothing 20 \times 60 \mathrm{~mm}$ (Fig. 4). Further samples were cut put into containers semi-solid casting machine and reheated to a predetermined temperature (temperature variations of 500, 510, 520, 530 and $540^{\circ} \mathrm{C}$ ). Once the temperature is reached on hold for 10 minutes so that the sample has a uniform temperature in the beginning and the middle, then performed a semi-solid casting process (the sample is injected into the mold cavity to force $100 \mathrm{kN}$ ). Samples were going (as-cast) and the results of the semi-solid casting characterized microstructure using metallurgical microscope Olympus BX-60M, hardness tested using the method Brinell hardness Wolpert He Testor 2n, the measurement of particle size by methods Jeffries and inspection SEM/EDS with JEOL type JSM-6360LA.

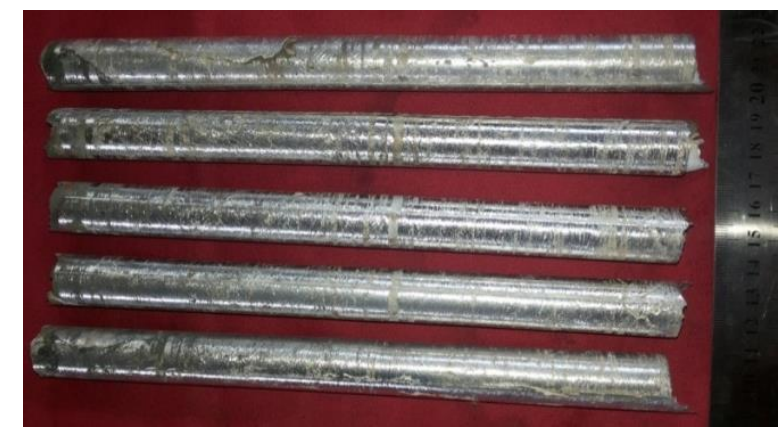

Figure 3. Casting process (as-cast) sized $\varnothing 20 \times 200 \mathrm{~mm}$ 


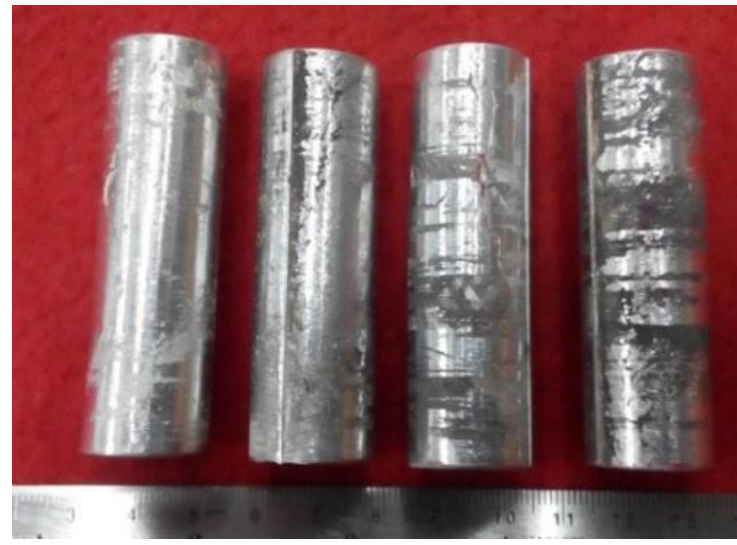

Figure 4. Raw material of semi-solid casting $\varnothing 20 \times 60 \mathrm{~mm}$.

\section{RESULTS AND DISCUSSION}

Analysis of Chemical Composition

Examination of the chemical composition of the alloy $\mathrm{Mg}-\mathrm{Al}-\mathrm{Zn}$ performed using the method of Atomic Absorption Spectroscopy (AAS) with the results shown in Table 1.

Tabel 1. The results of the examination of chemical composition of the alloy as-cast $\mathrm{Mg}-\mathrm{Al}-\mathrm{Zn}$

\begin{tabular}{lll}
\hline & \multicolumn{2}{l}{ Chemical composition (wt\% ) } \\
\multicolumn{1}{c}{ Element } & $\begin{array}{l}\text { Result of } \\
\text { analysis }\end{array}$ & $\begin{array}{l}\text { Standar AZ91D } \\
\text { (ASTM B94- } \\
\end{array}$ \\
& & 03 ) \\
\hline Aluminium (Al) & 9.49 & $8.3-9.7$ \\
Zinc (Zn) & 1.2 & $0.35-1.0$ \\
Magnesium (Mg) & 88.75 & Rest \\
Silicon $(\mathrm{Si})$ & - & 0.01 max. \\
Mangan $(\mathrm{Mn})$ & - & $0.15-0.5$ \\
Ferrous $(\mathrm{Fe})$ & - & 0.005 \\
Cupper $(\mathrm{Cu})$ & - & 0.03 max. \\
Nickel $(\mathrm{Ni})$ & - & 0.002 max. \\
\hline
\end{tabular}

\section{Results of Semi-solid Casting Process}

Samples of semi-solid casting process is shown in Fig. 5.

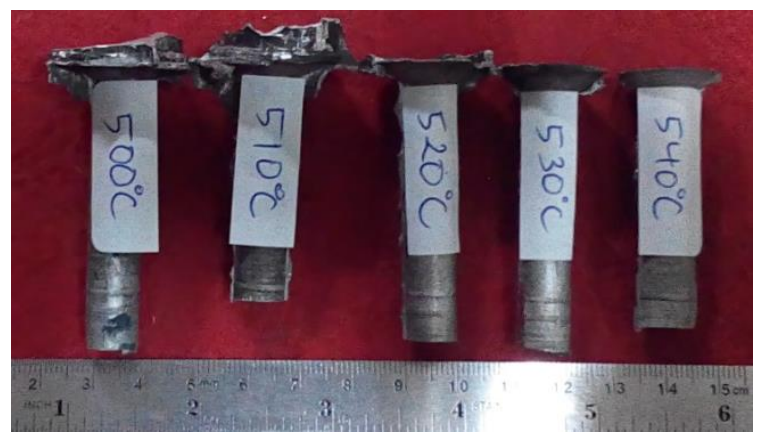

Figure 5. The results of the semi-solid casting process.

\section{Hardness testing}

The test results by using the method Brinell hardness $(2.5 \mathrm{~mm}$ diameter steel ball indenter and load $62.5 \mathrm{~kg}$ ) on a sample of as-cast and semi-solid casting results are shown in Fig. 6 and 7. While the percentage increase in the average hardness results of semi-solid casting compared to as-cast is shown in Fig. 8.

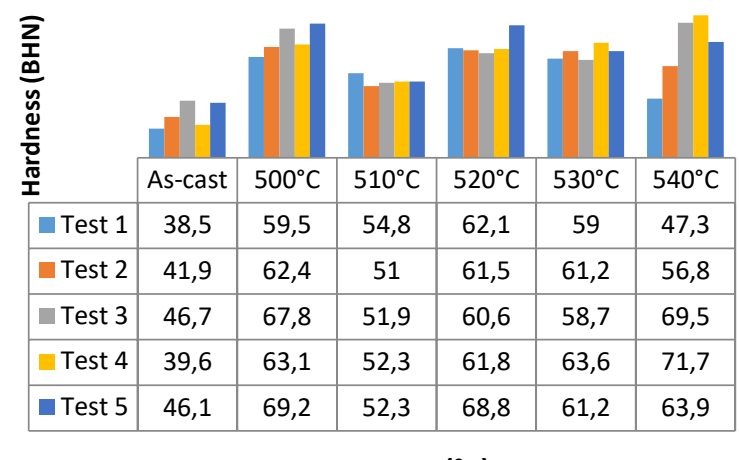

Temperatures $\left({ }^{\circ} \mathrm{C}\right)$

Figure 6. Hardness results of semi-solid casting of the temperature difference compared to as-cast.

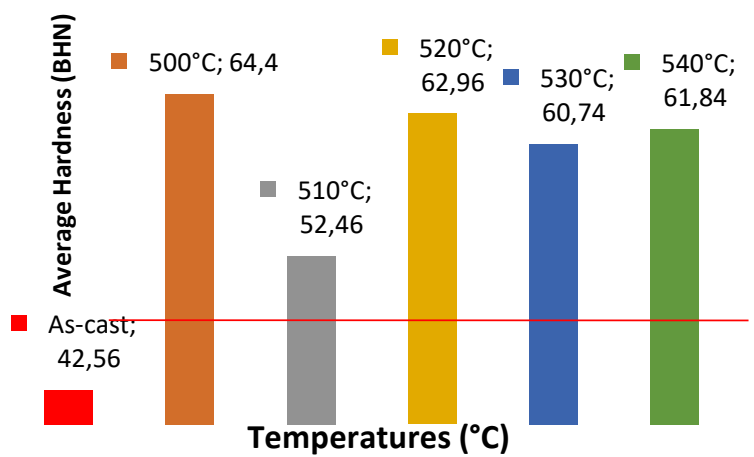

Figure 7. Hardness averages the semi-solid casting compared to as-cast.

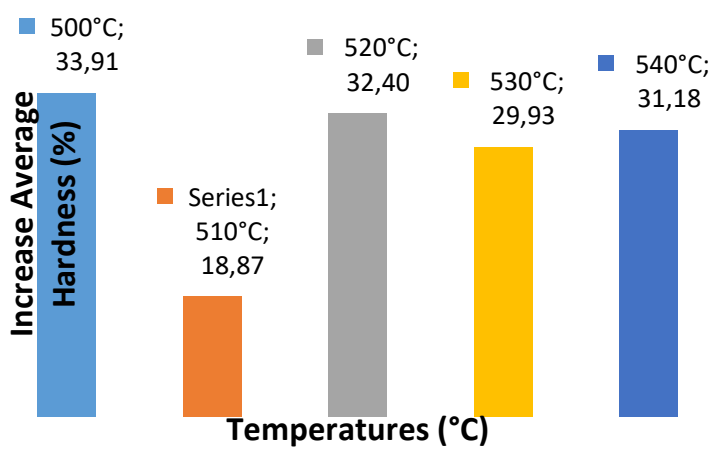

Figure 8. Increase in hardness averages the semi-solid casting of the as-cast.

\section{Microstructure Examination}

To see the changes and the variation in the sample between the as-cast and after the semi-solid casting process, microstructure examination using metallurgical microscope and Scanning Electron Microscope/Energy Dispersive Spectrometry (SEM /EDS). Microstructure examination results are shown in Table 2 and the results of SEM/EDS is shown in Fig. 9, 10 and 11. 
Tabel 2. Microstructure of AZ91D Mg alloy as-cast and semisolid casting results.

Fig. Sample condition Microstructures

a As-cast As-cast

$\mathrm{T}=500^{\circ} \mathrm{C}(100 \mathrm{X})$

$$
\beta-\mathrm{Mg}_{17} \mathrm{Al}_{12}
$$

$\alpha-\mathrm{Mg}$
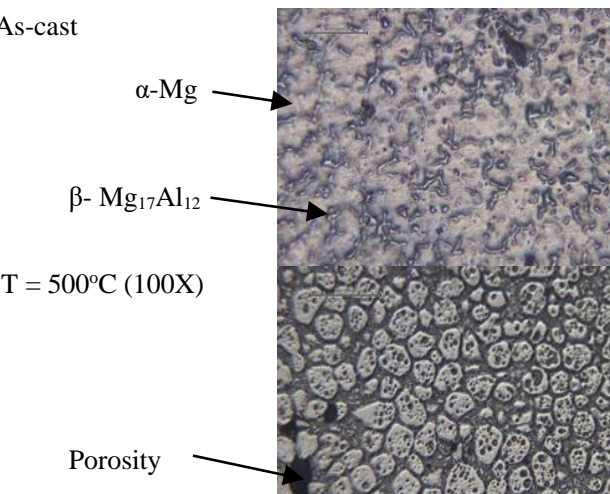

c $\quad \mathrm{T}=510^{\circ} \mathrm{C}(100 \mathrm{X})$

d

$\mathrm{T}=520^{\circ} \mathrm{C}(100 \mathrm{X})$

e $\quad \mathrm{T}=530^{\circ} \mathrm{C}(100 \mathrm{X})$

f $\quad \mathrm{T}=540^{\circ} \mathrm{C}(100 \mathrm{X})$
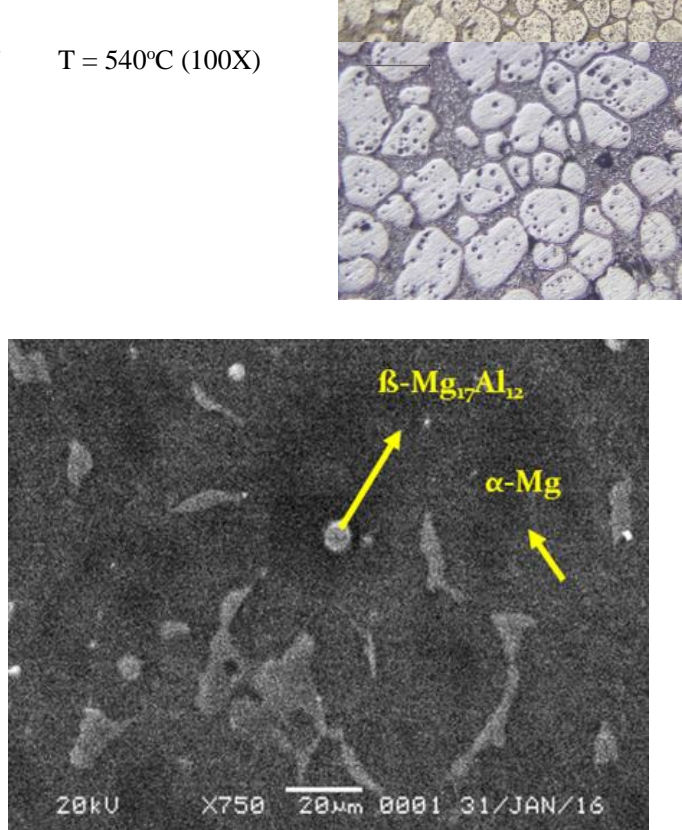

Figure 9. SEM examination, there are $\alpha-\mathrm{Mg}$ phase and intermetallic compound $\beta-\mathrm{Mg}_{17} \mathrm{Al}_{12}$

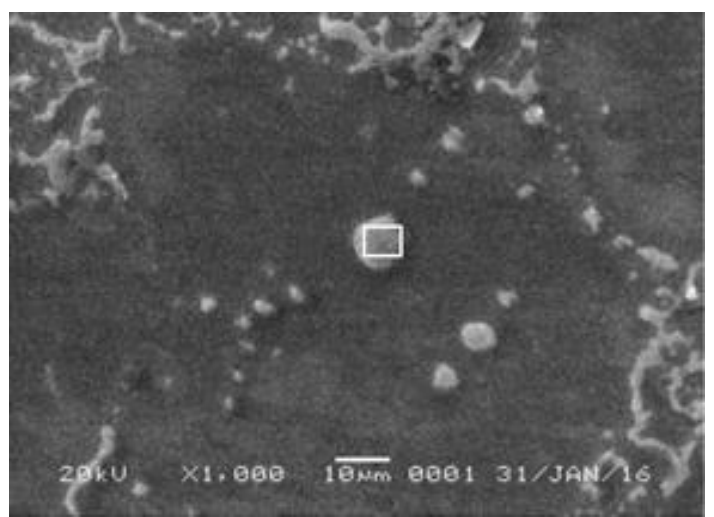

Figure 10. EDS spot area.

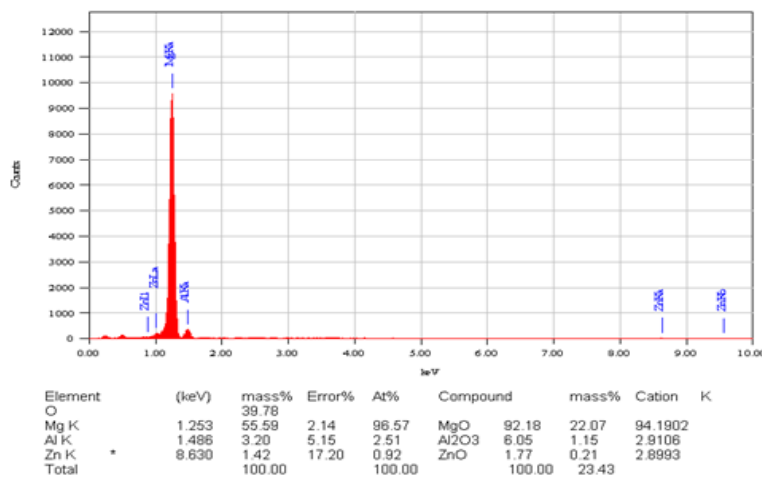

Figure 11. EDS examination results, there are $\alpha-\mathrm{Mg}$ phase and intermetallic compound $\beta-\mathrm{Mg}_{17} \mathrm{Al}_{12}$.

Measurement of particle size by using the Jeffries method shown in Fig. 12.

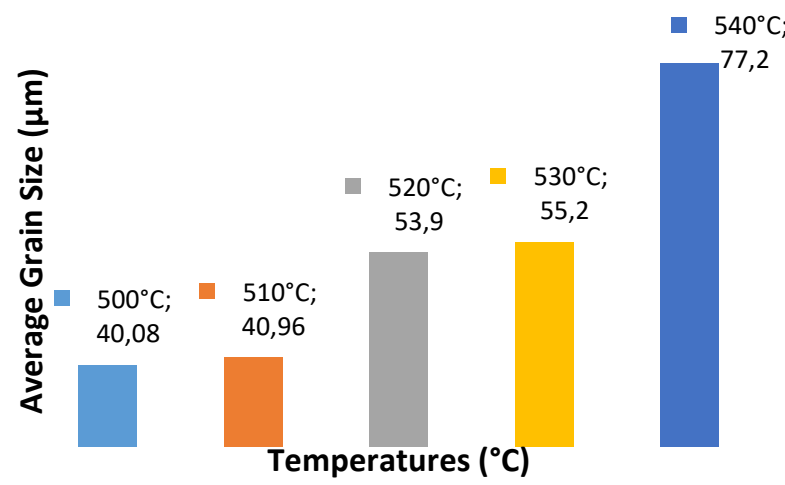

Figure 12. Comparison of the average price of major grain semi-solid casting results.

The results of examination of the chemical composition shown in Table 2 shows that the chemical composition of magnesium alloys AZ91D within the range of the chemical composition of the standard ASTM B94-03. Semi-solid casting process with variations in temperature from 500 to $540^{\circ} \mathrm{C}$ has been successfully carried out as shown in Fig. 5. Being filled cavity mold causing some metal out of the mold to form the flash of the tip end of the mold.

From the hardness test performed showed that samples of magnesium alloy semi-solid casting results have higher hardness than as-cast condition. Hardness results of semi-solid casting is in the range 
47.3 to 71.7 BHN (Fig. 6 and 7), higher than the ascast which is in the range of 38.5 to $46.7 \mathrm{BHN}$ violence. The increase in the average hardness of semi-solid casting results than going to be in the range of 18.87 to $33.91 \%$ (Fig. 8).

Increased hardness semi-solid casting results occur because of changes in the microstructure as shown in Table 2. Microstructures formed on AZ91D magnesium alloy either as-cast or semi-solid casting has the same phase, namely $\alpha-\mathrm{Mg}$ and $\beta-\mathrm{Mg}_{17} \mathrm{Al}_{12}$ intermetallic compounds, but the arrangement and formation mechanisms are different. In the as-cast, microstructure formed from slow cooling. Molten metal solidification process begins with the formation of dendrites structure continues to grow produce grains of $\alpha-\mathrm{Mg}$ large irregular and surrounded by intermetallic compounds $\beta-\mathrm{Mg}_{17} \mathrm{Al}_{12}$ (worm-like shaped) that have low hardness.

Microstructure results of semi-solid casting at all temperature variations indicate the same phase that form $\alpha-\mathrm{Mg}$ phase round with different sizes and grain around the $\alpha-\mathrm{Mg}$ intermetallic compounds are $\beta-\mathrm{Mg}_{17} \mathrm{Al}_{12}$. Globular $\alpha-\mathrm{Mg}$ grains caused by the force injection occurred during the semi-solid casting. Metal flow in a state of semi-solid that is moving at high speed causing the fragmentation of dendrite structure.

Relatively high temperatures cause dendrites to form fractions rounded grains are spread out evenly. Semi-solid casting temperature affects the large-small (fine or coarse) grain is formed. The lower the temperature of the grain will be smaller, because at lower temperatures item can not grow back. This is evidenced by the grain size measurements using the temperature $500^{\circ} \mathrm{C}$ Jeffries that has the smallest grain size is equal $40.08 \mu \mathrm{m}$ (Fig. 12).

SEM examination in Fig. 9 and 10 show that in going to the shape of the intermetallic compounds $\beta-\mathrm{Mg}_{17} \mathrm{Al}_{12}$ looks irregular. EDS examination showed oxide compounds formed in magnesium alloys (Fig. 11). This is possible because the protection is not perfect Argon shielding gas protects the molten metal alloys $\mathrm{Al}-\mathrm{Mg}-\mathrm{Zn}$ of oxygen so that the oxidation reaction occurs at the surface.

\section{CONCLUSION}

Semi-solid casting process can increase the hardness of magnesium alloy AZ91D. Hardness average resulting is in the range from 52.46 to 64.4 BHN. The highest hardness average obtained at $500^{\circ} \mathrm{C}$ 64.4 BHN. Persentase increase in hardness average highest obtained at $500^{\circ} \mathrm{C}$ amounted to $33.91 \%$. The microstructure formed from the semisolid casting is rounded and evenly composed of $\alpha$ $\mathrm{Mg}$ phase and intermetallic compound $\beta-\mathrm{Mg}_{17} \mathrm{Al}_{12}$. The smallest grain size $40.08 \mu \mathrm{m}$ obtained at $500^{\circ} \mathrm{C}$.

\section{ACKNOWLEDGMENT}

This research was supported by LPPM Unjani Number: 225/UNJANI/XI/2015; Date: 5 November 2015. The financial support is gratefully acknowledged. Also, the authors would like to thank and acknowledged to Pawawoi, Head of Metallurgical Engineering Department; Susanto Sambasri, Dean of Faculty of Engineering Unjani, who always encourage and support scientific activities and provide financial supports.

\section{REFERENCES}

[1] Watarai, H., (2006): Trend of Research and Development for Magnesium Alloys-Reducing the Weight of Structural Material in Motor Vehicles, Science and Technology Trends, quarterly review, 18 .

[2] Kojima, Y., (2001): Project of Platform Science and Technology for Advanced Magnesium Alloys, Materials Transactions, the Japan Institute of Metals, 42, 7, 1154-1159.

[3] Mutua, J., Kihiu, M., Rading, G.O., Kimotho, J.K., (2011): Use of Magnesium Alloys in Optimizing the Weight of Automobile: Current Trends and Opportunities.

[4] Xie, S., He, Y.F., Mi, X.J., (2007): Study on Semi-solid Magnesium Alloys Slurry Preparation and Continuous Roll-casting Process, Magnesium Alloys - Design, Processing and Properties.

[5] ASM Handbook, (1992): Phase Diagrams, Metals Park.

[6] ASM Handbook, (2008): Semi-solid Casting, Metals Park. 